ENTITA : Jurnal Pendidikan Ilmu Pengetahuan Sosial dan Ilmu-Ilmu Sosial http://ejournal.stainpamekasan.ac.id/index.php/entita

P-ISSN:2715-7555 E-ISSN:2716-1226

\title{
Pendidikan IPS Menjawab Tantangan Abad 21: Sebuah Kritik Atas Praktik Pembelajaran IPS di Sekolah Dasar
}

\author{
Arif Widodo ${ }^{1}$, Dyah Indraswati ${ }^{2}$, Deni Sutisna ${ }^{3}$, Nursaptini ${ }^{4}$, Ashar Pajarungi Anar ${ }^{5}$ \\ $1,2,3,4,5$ Universitas Mataram \\ arifwidodo@unram.ac.id,dyahindraswati@unram.ac.id, denisutisna@unram.ac.id, \\ nursaptini@unram.ac.id, ashar.pajarungianar@unram.ac.id
}

\section{Abstract}

The 21st century is full of developments in information technology. The development is getting faster and faster. The purpose of this literature study is to investigate 1) whether social studies learning in elementary schools is still relevant to the skills needed in the 21st century, 2) What skills are obtained from studying social studies in SD, 3) How should social studies be studied so that 21 st-century skills can be mastered. This study analyzes articles related to social studies learning and 21st-century skills. The articles analyzed are in the form of articles from empirical research and conceptual studies. The articles are taken from several accredited international and national journals. Concept analysis is carried out by synthesizing some of these articles to find the relevance of education to 21 st-century skills. The results of the study show that social studies learning is still relevant to 21 st-century skills development. Skills acquired through social studies learning include social skills, collaboration skills, networking skills, and communication skills. The demands of 21 st-century skills that require everyone to have social skills can be learned through social studies learning. For 21 st-century skills to be included in social studies learning, it is necessary to innovate learning models.

Keywords: social studies learning, 21st century skills, elementary school

Abstrak

Abad 21 sarat dengan perkembangan teknologi informasi. Perkembangan berjalan semakin semakin pesat. Tujuan dari studi literatur ini adalah untuk menyelidiki tentang 1) Apakah pembelajaran IPS di SD masih relevan dengan keterampilan yang dibutuhkan pada abad 21, 2) Keterampilan apa saja yang didapatkan dari mempelajari IPS di SD, 3) Bagaimana seharusnya mempelajari IPS agar keterampilan abad 21 dapat dikuasai. Kajian ini menganalisis artikel yang berkaitan dengan pembelajaran IPS maupun keterampilan abad 21. Artikel yang dianalisis berupa artikel hasil penelitian empiris maupun hasil kajian konseptual. Analisis konsep dilakukan dengan melakukan sintesis dari beberapa artikel tersebut untuk menemukan relevansi pendidikan dengan keterampilan abad 21. Hasil kajian menunjukkan bahwa pembelajaran IPS masih relevan dengan pengembangan keterampilan abad 21. Keterampilan yang didapatkan melalui pembelajaran IPS diantaranya kemampuan bersosialisasi, kemampuan berkolaborasi, kemampuan networking, dan kemampuan berkomunikasi. Tuntutan keterampilan abad 21 yang mengharuskan setiap orang untuk memiliki keterampilan sosial dapat dipelajari melalui pembelajaran IPS. Agar keterampilan abad 21 dapat termuat dalam pembelajaran IPS secara untuk maka perlu dilakukan inovasi model pembelajaran.

Kata Kunci: pembelajaran IPS, Keterampilan abad 21, sekolah dasar

Received:9 Oktober 2020;Revised: 5 Desember 2020; Accepted: 19 Desember 2020 


\section{Pendahuluan}

Pendidikan IPS telah diajarkan kepada siswa sejak lama di Indonesia. Pendidikan IPS di Indonesia pertama kali diperkenalkan pada tahun 1975. Perkembangan pendidikan IPS di Indonesia pada hakikatnya banyak mengadopsi dan mengadaptasi pemikiran sosial studies dari NCSS (Sapriya, 2017). Seiring berjalannya waktu perubahan demi perubahan terjadi pada pendidikan IPS. Perubahan terakhir pendidikan IPS dirasakan dengan bergulirnya kurikulum 2013. Perubahan terbesar terletak bagaimana komposisi pendidikan IPS disajikan. Semua bidang studi disajikan secara tematik terpadu tidak terkecuali dengan pendidikan IPS. Pendidikan IPS dalam praktik pengajarannya memang memerlukan inovasi. Terlebih lagi dalam menghadapi tantangan abad 21 pembelajaran IPS harus menyesuaikan diri (Schoenfeld, 1999). Pendidikan IPS merupakan salah satu mata pelajaran wajib pada jenjang sekolah dasar. Namun demikian, sejauh ini banyak kalangan yang memandang dengan sebelah mata pendidikan IPS. Mata pelajaran IPS dianggap sebagai mata pelajaran kelas dua. Hal ini terlihat dari pemberian jam pelajaran IPS lebih sedikit dari mata pelajaran lain. Tidak hanya itu pelajaran IPS selalu diberikan pada jam-jam terakhir disaat kondisi siswa telah penat dan lelah. Masih banyak kalangan beranggapan pendidikan IPS di SD tidak terlalu penting. Belum lagi menghadapi cara pandang siswa yang menganggap bahwa pelajaran IPS adalah pelajaran yang membosankan (Heafner, 2004). Maka dari itu rekonstruksi terhadap pendidikan IPS layak untuk dilakukan.

Masyarakat pada umumnya masih beranggapan bahwa kebutuhan yang harus dikuasai siswa dalam menghadapi abad 21 hanyalah kemampuan terhadap teknologi dan informasi. Bidang ilmu yang banyak diminati hanyalah yang berkaitan dengan ilmu eksak. IImu sosial hanya dipelajari sebatas menggugurkan kewajiban saja. Maka dari itu akhirakhir ini pendidikan IPS dan ilmu sosial lainnya sering terdengar akan dihapus dari kurikulum. Padahal ilmu sosial merupakan dasar dalam membentuk keterampilan sosial. Keterampilan sosial merupakan salah satu unsur terpenting dalam melakukan komunikasi, kolaborasi dan menjalin hubungan pada masyarakat abad 21. Mengesampingkan nilainilai keterampilan sosial dapat berakibat pada siswa yang semakin individualis dan tidak mampu bersosialisasi dengan baik. Banyak siswa yang tidak lagi mempunyai kepekaan sosial sehingga tidak lagi memperdulikan lingkungan sekitar. Kondisi seperti ini diperparah dengan penggunaan teknologi yang kurang bijak. Salah satunya adalah penggunaan media sosial yang berlebihan di kalangan pelajar (Sutisna et al., 2020). Penggunaan media sosial yang kurang bijak menyebabkan konflik dalam hidup bermasyarakat. Tidak 186

ENTITA Vol. 2 No. 2, Desember 2020 
jarang melalui penggunaan media sosial tersebut membuat penggunanya terjerat masalah hukum. Hal ini dapat terjadi karena etika dalam berhubungan sosial tidak lagi diperhatikan. Permasalahan ini mengindikasikan bahwa pemahaman konsep sosial pada kehidupan sehari-hari masih kurang. Hal ini tidak terlepas dari anggapan berbagai kalangan yang menyatakan bahwa pendidikan IPS itu tidak penting. Tidak dapat dipungkiri bahwa mengesampingkan nilai-nilai sosial dapat berakbiat buruk terhadap perilaku sosial siswa.

Berdasarkan latar belakang di atas penting dilakukan kajian benarkah pendidikan IPS itu tidak begitu penting? Masih relevankah pendidikan IPS dengan keterampilan abad 21? Keterampilan apa saja yang didapatkan dari mempelajari IPS di SD? Bagaimana seharusnya mengajarkan IPS agar keterampilan abad 21 dapat dikuasai? Melalui kajian ini diharapkan dapat menjadi tambahan referensi bagi guru dalam pengembangan pembelajaran IPS di sekolah dasar. Bagi pengambil kebijakan melalui kajian ini diharapkan menjadi pertimbangan dalam penyusunan kurikulum pembelajaran IPS, khususnya di sekolah dasar.

\section{Metode}

Kajian ini merupakan studi literatur. Kajian ini dilakukan dengan menganalisis literatur yang berkaitan dengan pendidikan IPS dan keterampilan abad 21. Data yang dianalisis adalah artikel dari jurnal internasional, jurnal nasional yang terakreditasi, buku dan sumber lain yang relevan. Pengumpulan data dengan cara membaca, mencatat dan mengolah data untuk memahami fenomena yang terjadi (Creswell, 2012). Analisis konsep dilakukan dengan melakukan sintesis dari beberapa artikel untuk menemukan relevansi pendidikan dengan keterampilan abad 21.

\section{Hasil dan Pembahasan}

Relevansi Pendidikan IPS dengan Keterampilan Abad 21

Diskusi tentang keterampilan abad 21 sebenarnya bukanlah hal baru. Bahkan komisi pendidikan Amerika telah membahasnya pada tahun 1983 (Bybee, 2009). Kini abad 21 telah hadir di depan mata. Abad 21 menyuguhkan kehidupan dunia tanpa batas. Perkembangan teknologi semakin pesat. Tantangan hidup ke depan semakin berat. Bagi yang tidak mampu bersaing akan hilang ditelan masa. Dalam menghadapi tantangan tersebut siswa perlu diberi bekal keterampilan abad 21 untuk memastikan daya saing mereka terhadap dunia global (Turiman, Omar, Daud, \& Osman, 2012). Melalui keterampilan yang dimiliki siswa diharapkan dapat melalui tantangan hidupnya secara 
Arif Widodo, Dyah Indraswati, Deni Sutisna dkk

mandiri di masa depan. Lebih lanjut Turiman et al., (2012) menyatakan bahwa keterampilan abad 21 yang dibutuhkan terdiri dari empat hal yaitu literasi digital, pemikiran inovatif, komunikasi yang efektif dan produktivitas yang tinggi. Terdapat juga sebuah penelitian yang menegaskan pentingnya menggunakan 4Cs dalam bidang pendidikan; Critical thinking (Berpikir kritis), Communication (Komunikasi), Collaboration (Kolaborasi), dan Creativity (Kreativitas) terutama untuk melatih siswa agar mempunyai keterampilan sosial dan berwawasan global (Nganga, 2019). Lebih lanjut diungkapkan juga bahwa globalisasi berkaitan dengan semua aspek kehidupan tidak terkecuali dengan bidang sosial (Nganga, 2019). Pernyataan tersebut memberi isyarat bahwa pendidikan IPS dalam dunia global masih dibutuhkan. Pendidikan yang berorientasi pada pemikiran sosial global dapat mendorong keingintahuan intelektual yang melampaui batas Negara dan budaya (Nganga, 2019).

Abad 21 yang sarat dengan perkembangan teknologi informasi berkaitan erat dengan aspek literasi, terutama iterasi digital. Namun demikian penguasaan terhadap teknologi bukanlah satu-satunya bidang yang harus dikuasai di era abad 21. Terdapat hasil penelitian yang menyatakan bahwa terdapat perbedaan antara literasi digital dengan keterampilan abad 21. Pada keterampilan abad 21 tidak selalu berhubungan dengan teknologi informasi dan komunikasi (van Laar, van Deursen, van Dijk, \& de Haan, 2017). Hal terpenting adalah menguasai keterampilan inti dan keterampilan kontekstual. Keterampilan inti terdiri dari kemampuan teknis, manajemen informasi, komunikasi, kolaborasi, kreativitas, berpikir kritis dan pemecahan masalah. Keterampilan kontekstual terdiri dari kesadaran etnis, budaya, fleksibilitas, pengarahan diri sendiri dan belajar sepanjang hayat (van Laar et al., 2017). Pernyataan tersebut sesuai dengan pendapat Kaufman, (2013) bahwa penguasaan teknologi penting tetapi masih ada lagi keterampilan hidup yang harus dikuasai salah satunya adalah pengendalian diri dan tanggung jawab sosial. Hal ini bermakna bahwa keterampilan yang harus dimiliki oleh seseorang harus kompleks. Artinya adalah tidak bisa hanya mengandalkan satu ketererampilan dengan mengesampingkan keterampilan yang lain. Begitu juga dalam menghadapi abad 21 tidak hanya membutuhkan kecanggihan dalam teknologi informasi tetapi juga harus memperhatikan aspek yang lain seperti keterampilan sosial.

Keterampilan yang berkaitan dengan aspek sosial adalah keterampilan berpikir kritis. Keterampilan tersebut diperlukan untuk membantu siswa dalam beradaptasi dengan situasi baru, fleksibel dan mampu menganalisis informasi yang didapat dengan baik (Dwyer, Hogan, \& Stewart, 2014). Kreativitas dan inovasi mempunyai pengaruh yang tidak 
diragukan lagi terhadap kehidupan masyarakat dan perkembangan ekonomi (Kaufman, 2013). Maka dari itu setiap kegiatan pembelajaran hendaknya diarahkan untuk pengembangan pemikiran kreatif, imajinatif dan inovatif (Kaufman, 2013). Perkembangan ekonomi abad 21 telah dikuasai kekuatan teknologi informasi. Perubahan tersebut membutuhkan individu yang memiliki kemampuan inovasi, beradaptasi, dan berpikir tingkat tinggi (Velez, 2012). Lebih lanjut menegaskan bahwa sungguhpun sekolah telah berkomitmen untuk menanggapi perubahan global akan tetapi program yang dilakukan belum jelas.

\section{Nilai-nilai Keterampilan Abad 21 dalam Pembelajaran IPS di Sekolah Dasar}

Pendidikan IPS pada hakikatnya adalah kumpulan dari ilmu-ilmu sosial yang disederhanakan (Rachmah, 2014). Merujuk pada pengertian Somantri pendidikan IPS pada jenjang sekolah dasar merupakan pernyederhanaan dari ilmu-ilmu sosial dan humaniora yang dikemas sedemikian rupa untuk tujuan pendidikan (Sapriya, 2017). IImu sosial yang termasuk dalam IPS diantaranya Sosiologi, Sejarah, Ekonomi dan Geografi. Melalui ilmu-ilmu tersebut banyak terdapat konsep-konsep ilmu sosial yang bermanfaat untuk keterampilan siswa. Pada ilmu sosiologi dipelajari tentang hubungan sosial dan bagaimana bekerjasama yang baik. Kedua konsep tersebut merupakan salah satu keterampilan sosial yang diperlukan dalam menghadapi abad 21. Pada ilmu sejarah terdapat nilai inspiratif kepada yang mempelajarinya. Melalui sejarah siswa dapat belajar dari orang-orang terdahulu yang telah sukses. Inspirasi ini jika dikembangkan dapat merangsang siswa untuk selalu kreatif dan inovatif. Kedua cra berpikir ini termasuk dalam berpikir kritis. Hal ini sesuai dengan salah satu hasil penelitian yang menyatakan bahwa untuk menjawab tantangan abad 21 dalam pembelajaran IPS di sekolah dasar adalah dengan menerapkan cara berpikir kritis dan problem solving (Indraswati, Marhayani, Sutisna, \& Widodo, 2020). Melalui pendidikan IPS sumberdaya manusia yang beradab, berkarakter dan berbudaya diharapkan dapat tercapai (Ridwan, 2016).

Keberadaan ilmu sosial jika dilihat dari kompetensi sikap yang harus dikuasai oleh siswa sesungguhnya telah tersedia mulai dari jenjang pendidikan dasar hingga pendidikan tinggi. Merujuk pada Mendikbud, (2018) kurikulum bertujuan untuk mencapai empat kompetensi yaitu kompetensi sikap spiritual, sikap sosial, pengetahuan dan keterampilan. Keempat kompetensi tersebut telah dicantumkan untuk setiap mata pelajaran. Khusus pada jenjang sekolah dasar terdapat sedikit perbedaan antara kompetensi sosial yang harus dikuasai siswa pada masing-masing tingkatan kelas. Rumusan kompetensi sosial 
Arif Widodo, Dyah Indraswati, Deni Sutisna dkk

untuk kelas I dan II yaitu "Menunjukkan perilaku jujur, disiplin, tanggung jawab, santun, peduli, dan percaya diri dalam berinteraksi dengan keluarga, teman, dan guru". Rumusan kompetensi sosial untuk kelas III dan IV di tambah dengan "tetangga", sedangkan untuk kelas $\mathrm{V}$ dan VI ditambah "tetangga dan cinta tanah air". Permendikbud tersebut juga menegaskan bahwa kompetensi sikap sosial bersama dengan kompetensi sikap spiritual dapat dicapai melalui pembelajaran tidak langsung, diantaranya keteladanan, pembiasaan dan budaya sekolah. Pembelajaran kedua kompetensi sikap tersebut hendaknya memperhatikan situasi dan kondisi masing-masing sekolah. Kedua kompetensi sikap tersebut merupakan sarana pembelajaran karakter terhadap peserta didik. Berdasarkan rumusan kompetensi sosial tersebut dapat diketahui bahwa nilai-nilai kerjasama serta kolaborasi sebagai wujud interaksi sosial sangat diutamakan. Hal ini membuktikan bahwa pendidikan IPS di SD telah membekali keterampilan abad 21, yaitu kolaborasi.

Kompetensi pengetahuan ( $\mathrm{KI} 3$ ) dan kompetensi keterampilan (KI) tiap-tiap mata pelajaran berbeda. $\mathrm{KI} 3$ dan $\mathrm{KI} 4$ tersebut kemudian dijabarkan dalam bentuk kompetensi dasar (KD). Pada mata pelajaran IPS di sekolah dasar kompetensi dasar dikembangkan berdasarkan disiplin ilmu, namun dalam penyajiannya dilakukan secara tematik sehingga tidak kelihatan batasan masing-masing bidang ilmu. Meskipun materi IPS disajikan secara tematik, namun masing-masing bidang ilmu masih dapat dikenali dari kompetensi dasar yang telah disajikan. Bidang ilmu geografi di kelas IV dapat dikenali dengan KD "Mengidentifikasi karakteristik ruang dan pemanfaatan sumber daya alam untuk kesejahteraan masyarakat dari tingkat kota/kabupaten sampai tingkat provinsi". Bidang ilmu sosiologi dan antropologi di kelas IV dapat dikenali dengan melihat KD yang berisi "Mengidentifikasi keragaman sosial, ekonomi, budaya, etnis, dan agama di provinsi setempat sebagai identitas bangsa Indonesia; serta hubungannya dengan karakteristik ruang". Bidang ilmu ekonomi di kelas IV dapat dikenali dengan melihat KD "Mengidentifikasi kegiatan ekonomi dan hubungannya dengan berbagai bidang pekerjaan, serta kehidupan sosial dan budaya di lingkungan sekitar sampai provinsi". Bidang ilmu sejarah di kelas IV dapat dikenali dengan melihat KD yang berisi tentang "Mengidentifikasi kerajaan Hindu dan/atau Buddha dan/atau Islam di lingkungan daerah setempat, serta pengaruhnya pada kehidupan masyarakat masa kini".

Bidang ilmu geografi di kelas $\mathrm{V}$ dapat dikenali melalui KD "Mengidentifikasi karakteristik geografis Indonesia sebagai Negara kepulauan/maritim dan agraris serta pengaruhnya terhadap kehidupan ekonomi, sosial, budaya, komunikasi, serta transportasi". Bidang ilmu sosiologi dan Antropologi dapat terlihat dari KD "Menganalisis 
bentuk bentuk interaksi manusia dengan lingkungan dan pengaruhnya terhadap pembangunan sosial, budaya, dan ekonomi masyarakat Indonesia". Bidang ilmu Ekonomi dapat dikenali melalui KD "Menganalisis peran ekonomi dalam upaya menyejahterakan kehidupan masyarakat di bidang sosial dan budaya untuk memperkuat kesatuan dan persatuan bangsa". Bidang ilmu sejarah dapat terlihat dari KD "Mengidentifikasi faktorfaktor penting penyebab penjajahan bangsa Indonesia dan upaya bangsa Indonesia dalam mempertahankan kedaulatannya".

Bidang ilmu geografi di kelas IV dapat terlihat dari KD "Mengidentifikasi karakteristik geografis dan kehidupan sosial budaya, ekonomi, politik di wilayah ASEAN". Bidang ilmu Sosiologi dan Antropologi dapat terlihat dari KD "Menganalisis perubahan sosial budaya dalam rangka modernisasi bangsa Indonesia". Bidang ilmu Ekonomi dapat terlihat dari KD "Menganalisis posisi dan peran Indonesia dalam kerja sama di bidang ekonomi, politik, sosial, budaya, teknologi, dan pendidikan dalam lingkup ASEAN". Bidang ilmu Sejarah dapat terlihat dari KD“Memahami makna proklamasi kemerdekaan, upaya mempertahankan kemerdekaan, dan upaya mengembangkan kehidupan kebangsaan yang sejahtera".

Jika dianalisis secara mendalam pada hakikatnya $\mathrm{KI}$ dan KD yang disiapkan oleh Kementrian Pendidikan dan Kebudayaan telah mengakomodasi nilai-nilai keterampilan abad 21 (Widodo, Indraswati, \& Sobri, 2019). Siswa telah difasilitasi untuk mengembangkan cara berpikir kritis, kolaborasi, berkomunikasi dalam memecahkan permasalahan. Keterampilan-keterampilan ini pada hakikatnya telah ada di dalam ilmuilmu sosial sebagai cikal bakal pendidikan IPS. Permasalahannya adalah seringkali muatan-muatan keterampilan abad 21 yang terdapat dalam konsep ilmu sosial tidak tersampaikan dengan baik dalam pembelajaran. Implikasinya pembelajarn IPS hambar tanpa nilai-nilai sosial yang merupakan kebutuhan terpenting dalam menghadapi tantangan abad 21.

\section{Pembelajaran IPS Berorientasi Keterampilan Abad 21}

Pembelajaran IPS di era abad 21 tengah menghadapi tantangan yang berat. Hal ini tidak terlepas dari tuntutan bahwa tujuan pendidikan IPS adalah membentuk warga negara yang baik. Dalam tataran ideal seharusnya siswa yang telah belajar IPS harus memiliki sikap dan perilaku yang baik. Namun realitanya banyak dijumpai siswa yang berperilaku buruk, suka melanggar aturan, dan tidak memiliki keterampilan sosial. Banyak ditemukan penyimpangan perilaku yang bertentangan dengan nilai-nilai sosial (Widodo, 
Arif Widodo, Dyah Indraswati, Deni Sutisna dkk

2020b). Sikap tidak mau menghargai perbedaan, individualis dan intoleran menjadi hal yang wajar di kalangan anak muda. Padahal sikap toleransi merupakan sikap yang sangat penting dalam menjaga persatuan dan kesatuan bangsa (Widodo et al., 2020). Pendidikan IPS sebagai pendidikan nilai tidak mampu memberikan makna bagi kehidupan siswa (Widodo, Akbar, \& Sujito, 2017). Hal ini menandakan bahwa misi pembelajaran IPS untuk membentuk warga negara yang baik dapat dikatakan gagal. Penyebab kegagalan pembelajaran IPS salah satunya disebabkan oleh model pembelajaran yang kurang inovatif. Sulit merubah paradigma pendidikan IPS sebagai mata pelajaran yang membosankan di kalangan siswa. Hal ini tidak terlepas dari penggunaan metode pembelajaran dan cara penyajian materi IPS di kelas yang cenderung hafalan tanpa makna (Widodo, 2020a).

Terdapat sebuah penelitian yang menyebutkan bahwa penggunaan teknologi merupakan salah satu solusi untuk meningkatkan motivasi belajar siswa pada mata pelajaran IPS (Heafner, 2004). Maka dari itu diperlukan inovasi agar pembelajaran IPS di kelas tidak membosankan, salah satunya dengan pemanfaatan teknologi. Hal ini senada dengan pernyataan Mason et al., (2000) yang menekankan bahwa guru IPS harus efektif mengintegrasikan teknologi dalam kegiatan belajar dan pembelajaran secara tepat. Melalui penggunaan teknologi cara pengajaran guru IPS harus berubah agar siswa dapat mengeksplor kemampuan yang dimilikinya. Pergeseran paradigma pada abad 21 menuntut adanya inovasi pendidikan dan pembelajaran tidak terkecuali dengan pendidikan IPS. Inovasi dalam pembelajaran IPS harus dilakukan dalam rangka beradaptasi dengan berbagai tantangan dan perubahan pada abad 21 (Ridwan, 2016). Berawal dari sini dapat dipahami bahwa peran guru dalam mempersiapkan siswa menuju tantangan abad 21 sangat penting. Terlebih lagi pada abad 21 Indonesia akan menyambut generasi emas yang diharapkan dapat berpikir kritis, kreatif, inovatif, kolaboratif dan berdaya saing global (Mahanal, 2014).

Kegagalan sekolah dalam mempengaruhi program sekolah diakibatkan oleh terabaikannya nilai-nilai dalam proses sosial sekolah (Giroux \& Penna, 1979). Lebih lanjut Giroux \& Penna, (1979) menyatakan bahwa dalam proses sosial tersebut terdapat kurikulum tersembunyi. Kurikulum tersembunyi dapat terlahir dari keteladanan dan pembiasaan melalui kultur sekolah (Sobri, Nursaptini, Widodo, \& Sutisna, 2019). Maka dari itu perubahan demi perubahan harus dilakukan agar proses pengembangan nilai-nilai sosial sebagai bekal peserta didik dalam menyambut abad 21. Perubahan telah dimulai dari perguruan tinggi. Dalam menyambut abad 21 universitas mulai mengembangkan 192 
hubungan yang lebih instensif dengan lingkungan masyarakat sekitar (Gibbons, 2008). Hal ini menunjukkan bahwa dalam proses penelitian dan penyebarluasan ilmu pengetahuan telah memperhatikan aspek sosial. Dalam hal ini universitas tidak hanya memikirkan kepentingannya sendiri namun yang lebih penting adalah melayani masyarakat (Gibbons, 2008). Aspek kolaborasi ini sangat penting agar misi dari pendidikan dapat tercapai, terlebih lagi dalam menghadapi tantangan abad 21 (Nursaptini et al., 2020).

Živkovil., (2016) berpendapat bahwa salah satu model pembelajaran abad 21 adalah dengan menggunakan model berpikir kritis. Model pembelajaran tersebut dirasa efektif dalam meningkatkan efisiensi pembelajaran proses penyusunan pengetahuan siswa. Model pembelajaran tersebut dapat memantau siswa mengembangkan keterampilan berpikir, mencari akar masalah, menyelesaikan masalah secara logis sebagai persiapan menuju persaingan global yang kompleks. Lebih lanjut dikatakan bahwa untuk menuju persaingan global siswa ditekankan komunikatif, kolaboratif, kreatif, inivatif, berpikir secara kritis analitis dan mampu menyelesaikan masalah dalam dunia nyata (Živkovil, 2016). Pembelajaran diarahkan menuju keterampilan berpikir tingkat tinggi. Melalui keterampilan tersebut siswa mampu berkomunikasi secara efektif, pemikir yang kritis dan dinamis, mampu memecahkan masalah, dan mempunyai keahlian tertentu sebaga pakar (Živkovil, 2016). Inovasi pembelajaran diperlukan untuk mendukung kegiatan pembelajaran yang melibatkan siswa berpartisipasi secara aktif. Hal ini sesuai dengan pendapat bahwa strategi inovatif dalam ilmu pendidikan berbasis media dapat membantu siswa mencapai keterampilan dan pengetahuan abad 21 (Dede \& Hall, 2010).

Teknologi tidak dapat dipisahkan lagi dalam dunia pendidikan. Terlebih lagi dalam studi sosial penggunaan teknologi sangat diperlukan. Inovasi yang berkaitan dengan keterampilan dan pengajaran abad 21 harus dilakukan. Indikator utamanya meliputi aspek informasi, komputasi, otomatisasi dan komunikasi (Farisi, 2016). Lebih lanjut dijelaskan bahwa integrasi teknologi dalam pembelajaran IPS telah mencerminkan inovasi pembelajaran di era global digital. Hal ini sesuai dengan visi dewan nasional untuk studi sosial (NCSS) yaitu bermakna, kuat, berbasis nilai, menantang dan aktif. Visi tersebut juga telah mendukung keterampilan inti abad 21 diantaranya inovasi, keterampilan belajar, literasi teknologi informasi, dan keterampilan hidup (Farisi, 2016). Sedikit berbeda dengan sebuah penelitian pada suatu Negara berkembang yang menyatakan bahwa strategi pembelajaran berbasis computer tidak berpengaruh secara signifikan terhadap keterampilan sosial anak sekolah (Ige, 2019). Sungguhpun demikian penggunaan media 
Arif Widodo, Dyah Indraswati, Deni Sutisna dkk

pembelajaran berbasis computer tetap dapat digunakan untuk melengkapi pembelajaran tradisional. Jika IPS dihubungkan dalam kewarganegaraan, sebuah studi di Amerika Serikat berpendapat perlunya rekonstruksi kurikulum. Rekontruksi kurikulum terutama yang berkaitan rasa patriotisme dan nasionalisme dalam perspektif global (Myers, 2006).

\section{Kesimpulan}

Abad 21 tidak hanya mementingkan kemajuan dalam bidang teknologi informasi. Aspek sosial menjadi salah satu hal yang harus diperhatikan. Globalisasi dan kemajuan teknologi telah nyata merubah tatanan sosial dan budaya manusia. Tantangan atas perubahan sosial tersebut harus dipersiapkan. Pendidikan IPS salah satu banteng dalam memahami fenomena tersebut. Melalui pendidikan IPS dapat dipelajari bagaimana bersosialisasi, menyesuaikan diri, menjalin kerjasama (kolaborasi), berkomunikasi, membangun relasi, berpikir analisis, dan berpikir kritis. Hal ini menunjukkan bahwa IPS masih dibutuhkan untuk dipelajari dan masih relevan dengan abad 21. Hanya saja guru IPS tidak boleh anti perubahan. Dalam hal ini pendidikan IPS harus mengikuti pekembangan zaman. Metode pembelajaran harus diperbarui dan yang lebih penting lagi konten pelajaran harus lebih kontekstual sesuai dengan kebutuhan peserta didik.

\section{Saran}

Berdasarkan simpulan di atas dapat dipahami bahwa pendidikan IPS di sekolah masih relevan dengan pembelajaran abad 21. Terdapat beberapa saran yang dapat diberikan kepada para guru agar lebih kreatif dan inovatif dalam menyampaikan materi pendidikan IPS kepada peserta didik. Kepada pengambil kebijakan dalam hal ini perumus kurikulum hendaknya KI dan KD pendidikan IPS selalu diperbarui untuk menyesuaikan kebutuhan zaman.

\section{References}

Bybee, R. W. 2009. A Commissioned Paper Prepared for A Workshop on Exploring The Intersection Education and The Development of 21st Century Skills. Science And Technology, 26(2001), 295-300. Retrieved from http://sites.nationalacademies.org/cs/groups/dbassesite/documents/webpage/dbasse_073327.pdf

Creswell, J. W. 2012. Educational Research, planning, conducting and evaluating quantitative and qualitative research (Fourth; Matthew Buchholtz, Ed.). Boston, USA: Pearson.

Dede, C., \& Hall, L. 2010. Technological Supports for Acquiring 21 st Century Skills International Encyclopedia of Education. Education, 23. Retrieved from http://learningcenter.nsta.org/products/symposia_seminars/iste/files/Technological_Su pport_for_21stCentury_Encyclo_dede.pdf

Dwyer, C. P., Hogan, M. J., \& Stewart, I. 2014. An integrated critical thinking framework for the 21st century. Thinking Skills and Creativity, 12, 43-52. 
https://doi.org/10.1016/j.tsc.2013.12.004

Farisi, M. I. 2016. Developing the 21st-century social studies skills through technology integration. Turkish Online Journal of Distance Education, 17(1), 16-30. https://doi.org/10.17718/tojde.47374

Gibbons, M. 2008. Higher Education in the 21st Century. Higher Education Policy, 21(2), 147-150. https://doi.org/10.1057/hep.2008.10

Giroux, H. A., \& Penna, A. N. (1979). Social Education in the Classroom: The Dynamics of the Hidden Curriculum. Theory \& Research in Social Education, 7(1), 21-42. https://doi.org/10.1080/00933104.1979.10506048

Heafner, T. (2004). Using technology to motivate students to learn social studies. Contemporary Issues in Technology and Teacher, 4(1), 42-53. Retrieved from http://www.citejournal.org/vol4/iss1/socialstudies/article1.cfm

Ige, O. A. (2019). Impact of computer-assisted instructional strategy on schoolchildren's social skills. Journal of Social Studies Education Research, 10(4), 490-505. Retrieved from https://jsser.org/index.php/jsser/article/viewFile/1389/427

Indraswati, D., Marhayani, D. A., Sutisna, D., \& Widodo, A. (2020). Critical Thinking Dan Problem Solving Dalam Pembelajaran Ips Untuk Menjawab Tantangan. Sosial Horizon, 7(1), 12-28. https://doi.org/10.31571/sosial.v7i1.1540

Kaufman, K. J. (2013). 21 Ways to 21st Century Skills: Why Students Need Them and Ideas for Practical Implementation. Kappa Delta Pi Record, 49(2), 78-83. https://doi.org/10.1080/00228958.2013.786594

Mahanal, S. (2014). Peran Guru dalam Melahirkan Generasi Emas dengan Keterampilan Abad 21. Seminar Nasional Pendidikan HMPS Pendidikan Biologi FKIP Universitas Halu Oleo, (September), 1-16. Retrieved from https://www.researchgate.net/profile/Susriyati_Mahanal/publication/319746366

Mason, C., Berson, M., Diem, R., Hicks, D., Tech, V., Lee, J., \& Dralle, T. (2000). Guidelines for using technology to prepare social studies teachers. Contemporary issues in technology and teacher education Guidelines for Using Technology to Prepare Social Studies Teachers. 1(1), 107-116.

Mendikbud. Peraturan Menteri Pendidikan Dan Kebudayaan Republik Indonesia Nomor 37 Tahun 2018. , mendikbud § (2018).

Myers, J. P. (2006). Rethinking the social studies curriculum in the context of globalization: Education for global citizenship in the U.S. Theory and Research in Social Education, 34(3), 370-394. https://doi.org/10.1080/00933104.2006.10473313

Nganga, L. (2019). Preservice teachers' perceptions and preparedness to teach for global mindedness and social justice using collaboration, critical thinking, creativity and communication (4cs). Journal of Social Studies Education Research, 10(4), 26-57. Retrieved from https://jsser.org/index.php/jsser/article/download/1262/407

Nursaptini, N., Anar, A. P., Indraswati, D., Wiododo, A., Novitasari, S., \& Sutisna, D. (2020). School Operational Assistance and Challenges of Communities' Participation at Madrasah Tsanawiyah in Central Lombok. Proceedings of the 1st Annual Conference on Education and Social Sciences (ACCESS 2019), 465(Access 2019), 279-282. https://doi.org/10.2991/assehr.k.200827.070 
Rachmah, H. (2014). pengembangan profesi pendidikan IPS. Bandung: Alfabeta.

Ridwan, A. E. (2016). Pendidikan IPS dalam membentuk SDM beradab. JURNAL PENDIDIKAN ILMU SOSIAL, 23(1), 27-35. https://doi.org/10.17509/jpis.v23i1.2060

Sapriya. (2017). Pendidikan IPS: Konsep dan Pembelajaran (8th ed.). Bandung: PT Remaja Rosda Karya.

Schoenfeld, A. H. (1999). Looking Toward the 21st Century: Challenges of Educational Theory and Practice. Educational Researcher, 28(7), 4-14. https://doi.org/10.3102/0013189X028007004

Sobri, M., Nursaptini, N., Widodo, A., \& Sutisna, D. (2019). Pembentukan karakter disiplin siswa melalui kultur sekolah. Harmoni Sosial: Jurnal Pendidikan IPS, 6(1), 61-71. https://doi.org/10.21831/hsjpi.v6i1.26912

Sutisna, D., Widodo, A., Nursaptini, N., Umar, U., Sobri, M., \& Indraswati, D. (2020). An Analysis of the Use of Smartphone in Students' Interaction at Senior High School. Proceedings of the 1st Annual Conference on Education and Social Sciences (ACCESS 2019), 465(Access 2019), 221-224. https://doi.org/10.2991/assehr.k.200827.055

Turiman, P., Omar, J., Daud, A. M., \& Osman, K. (2012). Fostering the 21st Century Skills through Scientific Literacy and Science Process Skills. Procedia - Social and Behavioral Sciences, 59, 110-116. https://doi.org/10.1016/j.sbspro.2012.09.253

van Laar, E., van Deursen, A. J. A. M., van Dijk, J. A. G. M., \& de Haan, J. (2017). The relation between 21st-century skills and digital skills: A systematic literature review. Computers in Human Behavior, 72, 577-588. https://doi.org/10.1016/j.chb.2017.03.010

Velez, A. (2012). Preparing Students for the Future - 21St Century Skills (Southern California). Retrieved from http://digitallibrary.usc.edu/utils/getfile/collection/p15799coll3/id/26131/filename/26012.pdfpage/page/1

Widodo, A. (2020a). Nilai Budaya Ritual Perang Topat Sebagai Sumber Pembelajaran IPS Berbasis Kearifan Lokal di Sekolah Dasar. Gulawentah:Jurnal Studi Sosial, 5(1), 116. https://doi.org/10.25273/gulawentah.v5i1.6359

Widodo, A. (2020b). Penyimpangan Perilaku Sosial Ditinjau dari Teori Kelekatan Bowlby (Studi Kasus Terhadap Anak Tenaga Kerja Wanita di Lombok Barat). ENTITA: Jurnal Pendidikan IImu Pengetahuan Sosial Dan IImu-IImu Sosial, 2(1), 35-50. https://doi.org/http://dx.doi.org/10.19105/ejpis.v1i2.3187

Widodo, A., Akbar, S., \& Sujito, S. (2017). Analisis nilai-nilai falsafah Jawa dalam buku pitutur luhur budaya Jawa karya Gunawan Sumodiningrat sebagai sumber belajar pada pembelajaran IPS. Jurnal Penelitian Dan Pendidikan IPS (JPPI), 11(2), 152179. Retrieved from http://ejournal.unikama.ac.id/index.php/JPPI/article/download/-

Widodo, A., Indraswati, D., \& Sobri, M. (2019). Analisis Nilai-Nilai Kecakapan Abad 21 dalam Buku Siswa SD/MI Kelas V Sub Tema 1 Manusia dan Lingkungan. Tarbiyah: Jurnal IImiah Kependidikan, 8(2), 125. https://doi.org/10.18592/tarbiyah.v8i2.3231

Widodo, A., Maulyda, M. A., Fauzi, A., Sutisna, D., Nursaptini, N., \& Umar, U. (2020). Tolerance Education Among Religious Community Based on the Local Wisdom Values in Primary Schools. Proceedings of the 1st Annual Conference on Education and Social Sciences (ACCESS 2019), 465(Access 2019), 327-330. https://doi.org/10.2991/assehr.k.200827.082 
Živkovil:, S. (2016). A Model of Critical Thinking as an Important Attribute for Success in the 21st Century. Procedia - Social and Behavioral Sciences, 232(April), 102-108. https://doi.org/10.1016/j.sbspro.2016.10.034 
Arif Widodo, Dyah Indraswati, Deni Sutisna dkk 